\title{
UM CORPO TECNORGÂNICO PARA A ERA DA \\ CIBERCULTURA: \\ EFEITOS SOBRE O SEXO E O GÊNERO
}

\author{
A TECHNO-ORGANIC BODY TO THE ERA OF \\ CYBERCULTURE: \\ EFFECTS ON SEX AND GENDER
}

\section{Dina Maria Machado Andréa Martins Ferreira* Tibério Caminha}

\section{RESUMO}

O presente trabalho busca discutir as teorias contemporâneas aplicadas aos estudos do corpo, gênero e sexualidade e fazer um levantamento sobre as relações entre tecnologia e sujeito em um momento histórico que chamamos de 'pós-humanismo'. Explora também a necessidade de uma revisão das categorias discretas da sexologia do século XX, já que a dinâmica da cibercultura está desinstitucionalizando subjetividades e identidades sociais por meio de novos espaços de sociabilidade (ciberespaço) e novos padrões de comportamento sexual. A crítica deste artigo caminha em direção à desconstrução de políticas culturais que estabelecem a conexão entre condições materiais de produção e práticas sexuais ditas saudáveis na sexuação do corpo. Isto é, refletimos sobre os efeitos do trabalho material e do simbolismo social nas identificações de gênero e o cinismo que transpassa a erotologia tradicional.

Palavras-chave: cibercultura, corporalidade, sexualidade.

\section{ABSTRACT}

This paper aims at discussing contemporary theories applied to the studies of body, gender and sexuality and providing a review of the relationship between technology and subject in a historical moment we call post-humanism. It also explores the need for a review of discrete categories of sexology of the twentieth century, since the dynamics of cyberculture is deinstitutionalising subjectivities and social identities through new spaces of sociability (cyberspace) and new patterns of sexual behavior. This article's critique offers a path toward the deconstruction of cultural politics that establish the connection between material conditions of production and sexual practices said to be healthy in the sexualization of the body. That is, we reflect on the effects of material work and social symbolism in gender identifications and the cynicism that runs through the postmodern erotology.

Keywords: cyberculture, corporeality, sexuality.

\footnotetext{
* Universidade Estadual do Ceará, Fortaleza (CE), Brasil. dinaferreira@terra.com.br; Universidade Estadual do Ceará, Fortaleza (CE), Brasil.tiberiocaminha@gmail.com
} 


\section{INTRODUÇÃO}

Em 1982, a narrativa ficcional Blade Runner - o Caçador de Androides, dirigida por Ridley Scott, já preconizava uma relação de quase interdependência entre o corpo e as novas tecnologias no século XXI. Ainda que distantes de uma corporalidade clonada e biônica - chamada de replicante (replicant) no filme -, a aplicação dos conhecimentos e princípios tecnológicos a outros sistemas de atividade humana tem revolucionado os modos pelos quais interagimos com o Outro e estendemos nossos limites para além de um corpo dito 'natural', mas não por isso o transformamos em 'anormal'. O impacto cultural do tipo de ficção científica 'da alta tecnologia e do baixo nível de vida' (bigh tech, low life), também conhecida por cyberpunk, ganhou novos contornos com os fenômenos sociais intrínsecos à Internet (redes sociais, negócios e entretenimentos virtuais), a ponto de fazer oportuna a pergunta: vivemos em uma realidade virtual ou uma 'virtualidade real'?

Talvez a resposta seja: habitamos uma 'realidade alienígena', pois que, na presente dinâmica cultural, o virtual transpassa e orienta a materialidade das coisas pela imaterialidade e vice-versa, tornando difícil entender o Deus surgido da máquina (Deus ex machina). A cibercultura, além de desestruturar a tradição das interações sociais, também rompe com a visão naturalista do corpo. E na transgressão da ordem preexistente, se, por um lado, redes sociais virtuais, cirurgia plástica e body building são assuntos ordinários, por outro, novos tipos de interação, práticas de modificação e extensão corporal continuam sendo temas tabus. O 'Eu-máquina', inconsciente dos efeitos dos elementos exteriores que moldam sua própria corporificação, também se transforma em um agente ativo de recriação do sexo e ressignificação do gênero.

A finalidade deste artigo é pôr em questionamento o simbolismo social que aponta para a inevitabilidade de um gênero que não fuja à anatomia (idealizada como uma norma da natureza) e de um exemplo de afetividade que só é realizável pela diferença de dois corpos (idealizado como uma questão de química) tendo como ponto de partida o choque das inovações tecnológicas com a cultura, a práxis e o sujeito. Nesse sentido, refletimos que "é a tecnologia contemporânea que cria o ambiente e as condições necessárias para a remodelagem física e mental dos novos sujeitos" (COUTO, 2013, p. 174). Em seguida, discutimos sobre a emergência da redefinição do conceito de gênero no presente contexto histórico, porquanto continua apenas identificação correlata e significação naturalizada. E, por fim, fazemos ver que o trabalho material da sociedade também dá vazão a uma nova percepção de sexualidade que se opõe ao binário homo/heterossexual e à dicotomia normal/anormal. 


\section{REALIDADE ALIENÍGENA E CORPO POLIMÓRFICO}

$\mathrm{Na}$ ocasião em que Marx disse que "toda vida social é essencialmente prática" (1998, p. 102-103), esse filósofo deixou clara sua convicção de que "são as condições materiais da vida que determinam a consciência e há uma relação dialética entre as necessidades materiais e as ideias dos homens" (AMORETTI, 2010, p. 61). Todavia, o pensamento da época não deu conta de todas as implicações do trabalho material da sociedade na produção de subjetividades e na formação de corporeidades - as maneiras pelas quais utilizamos o corpo como instrumento para nos relacionarmos com o mundo.

Com o salto qualitativo da cibernética nas últimas décadas, parece inoportuno continuarmos chamando este momento histórico de pós-modernidade, quando o termo mais apropriado é provavelmente 'pós-humanismo' - expressão que se origina da ficção científica. Dito de outro modo, a tecnologia avançada, a realidade virtual e a dinâmica cultural nos colocaram em um estado para além do humano, em um lugar do qual "surge um novo problema filosófico: redefinir o que é ser humano" (COUTO, 2013, p. 175). A própria realidade do sujeito, por exemplo, não pode ser sintetizada à materialidade das coisas, visto que ele está submerso em um mar de ondas eletromagnéticas, sobrecarregadas de informação, e situado em um novo lugar de sociabilidade - o ciberespaço. Uma vez no ciberespaço, 'ser humano' é também ser imaterial, pois matéria é localidade e continuidade e nesse lugar existem novas combinações espaço-tempo, integração e conexão (LÉVY, 1996).

Se a realidade 'pós-humana' é fruto de ambas as combinações, localidade/ continuidade e não-localidade/descontinuidade, por que a experiência do indivíduo estaria constrangida às limitações de seu corpo? Para que a realidade seja percebida como fatos sociais, faz-se necessária a presença de um observador/intérprete coletivo: o Alter (o Outro [a sociedade]), o Ego (o Eu [o sujeito]) e o Objeto (a coisa [a tecnologia, no caso]) - o que Marková (2006) chama de tríade dialógica AlterEgo-Objeto. Nesses termos, sociedade, sujeito e tecnologia são uma só coisa: o real. No entanto, mesmo que essa visão quebre com qualquer concepção de mundo cartesiana/individualista, ela não implica cosmovisão totalitária/coletivista, mas relacional e analógica: viver nesta realidade dá a entender relacionar-se com o Alter e com o Objeto, e que tanto um quanto o outro, e também a ideia de Eu próprio, podem assumir valores contínuos, se não instáveis.

Traçando um paralelismo com o dito de Marx (1998), chegamos à conclusão de que a realidade 'pós-humana' só é percebida como tal através das formas de vida que ela torna possíveis e que a tornam possível. Melhor ainda, a sociedade da alta 
tecnologia exige a imprevisibilidade e a adaptabilidade de um novo sujeito que se ajuste a ela (COUTO, 2013); exigências essas que são refletidas no superficial (no corpo físico) e ecoam no profundo (na percepção de mundo). E, em uma realidade alienígena, o polimorfismo tornou-se a nova natureza do humano.

Talvez este seja o momento necessário para repensar ainda mais a materialidade do corpo e desnaturalizá-lo. "Estar apto" a existir em meio à alta tecnologia "significa ter um corpo flexível, absorvente e ajustável, pronto para viver sensações ainda não testadas e impossíveis de descrever de antemão" (BAUMAN, 2001, p. 91), para experiências tecno-humanas que este ambiente faz acontecer. Portanto, aptidão, ou adequação, diz sobre situar o corpo no campo da ação, se não das práticas sociais, e não estudá-lo a partir de condições biológicas e trans-históricas, pois

O corpo é provisório, mutável e mutante, suscetível a inúmeras intervenções consoante o desenvolvimento científico e tecnológico de cada cultura bem como suas leis, seus códigos morais, as representações que cria sobre os corpos, os discursos que sobre ele produz e reproduz. [...] O corpo não é apenas um corpo. É também seu entorno (GOELLNER, 2013, p. 30-31).

Analisar o corpo apenas através da perspectiva naturalista é um erro, porquanto se nega a sua historicidade. Desde a Revolução Industrial (século XIX), nota-se uma sincronia entre os meios de produção e os modelos de estética: se, por um lado, a criação da máquina a vapor foi inspirada no corpo como produtor de energia, por outro, as leis da termodinâmica (da energia produtiva) deram subsídios para a construção de uma estética sadia e higiênica (GOELLNER, 2013). Lembremos que o Capitalismo é um sistema econômico que investe no corpo como um projeto de produtividade. E nesse novo projeto de humano, o capitalismo industrial fez com que toda a atenção estivesse voltada para a normatização explícita da aparência, a padronização estética do indivíduo (LIPOVETSKY, 2004). A aparência física baseada em imposições modelares passou a servir de justificativa, até mesmo, para a divisão de classes: o corpo simétrico e moderado é associado à boa educação e o assimétrico e excessivo à má.

O corpo pós-moderno seria, então, o fruto da internalização da ideologia do capitalismo? Para Foucault (1988), a realidade biopolítica do corpo não é internalizada pelo sujeito, mas incorporada ao seu estilo de vida pela educação que recebe das instituições sociais (prisão, escola, cultura etc.). Isto é, a ideologia da máxima produtividade, que transforma o corpo social e o corpo individual em um só, está implícita nas interações sociais e nos objetos culturais (propagandas, livros, filmes etc.), fazendo o indivíduo reproduzir tal percepção de mundo de modo acrítico e estabelecer uma realidade idealizada. Recordemos também que 
a tendência dos discursos institucionais é transformar proposições ideológicas em senso comum sob a rubrica de 'conhecimento', e, no senso comum, 'conhecimento' torna-se 'natureza humana', visto que é tido como 'algo dado'.

A noção foucaultiana de incorporação é útil ao entendimento dos processos pelos quais os elementos exteriores (o Alter e o Objeto, no caso) revestem a superfície do corpo, dando a impressão errônea de que o mesmo é apenas a causa do momento histórico, e não também o efeito. Mas, para que essa realidade seja tida pelo Ego como uma 'verdade absoluta', é profícuo o acordo da incorporação com o conceito freudiano de introjeção (FREUD, 1996). A introjeção parte do princípio de alteridade, tal como a identificação, e diz sobre as maneiras pelas quais o Ego converte o mundo exterior (a sociedade e a tecnologia, no caso do estudo) em percepção própria - a parir da qual se naturalizam certos dualismos (semelhante/ dessemelhante ou igual/desigual, por exemplo). Em suma, identificando-se com tal realidade, ou não, todos os elementos constituintes da mesma são internalizados pela 'célula individual'. Daí termos afirmado anteriormente que o corpo é tanto imagem exterior quanto interior de seu 'entorno'.

Para o sujeito, investir na aparência física é uma maneira de transitar pelas várias territorialidades desviando-se de certos preconceitos (do elitismo, por exemplo). O culto ao corpo tornou-se uma tática de sobrevivência social, pois a homogeneização do parecer teve como efeito colateral a desorganização da "ordem imutável da aparência tradicional e as distinções intangíveis entre grupos" (LIPOVETSKY, 1989, p. 41). Observa-se aqui que o 'corpo-santuário' tem uma função simbólico-social, logo, ir contra o condicionamento social e genético é uma questão de ajustar-se às contingências de uma realidade em constante mudança. Enquanto o desenvolvimento tecnológico antes da Revolução Industrial demorava décadas para acontecer, nos dias de hoje, o Alter-Ego-Objeto sai de uso, ou de moda, em pouco tempo. Com as inovações tecnológicas a todo o momento, há também necessidade de atualização (upgrade) ininterrupta do humano.

Todavia, devemos usar de cautela com reducionismos. Ao mesmo tempo em que é necessário dar atenção aos aspectos materiais de uma ideologia específica, o indivíduo tem sua importância como agência com interesses particulares. Caso exista uma 'tática de adequação' do corpo à norma, há também a objetivação do mesmo como um tipo de resistência. Os Ursos (Bears) - homens gays que têm muito pêlo e barba, grandes e pesados -, uma subcultura da Comunidade LGBT ${ }^{1}$, salientam a diferença pelas marcas de um tipo específico de estética em oposição

\footnotetext{
${ }^{1}$ Lésbicas, gays, bissexuais, travestis, transgêneros e transexuais.
} 
ao estereótipo do corpo 'plástico', artificial, trabalhado à exaustão nas academias e supervalorizado em nossa cultura. Outras tribos urbanas² (Punks, Hippies, Góticos etc.) valem-se da corporeidade como um modo de tornar visível o choque de interesses sociais, seja pelo vestuário, pelas formas ou pelo comportamento - a linguagem gestual é extensão corpo. Tais ilustrações dão a entender transgressão, não passividade e inércia.

Ainda que os padrões de estética estejam disponíveis nos discursos sociais, sugerindo tipos de beleza masculina e feminina, o sujeito desempenha um papel ativo no trânsito de substâncias químicas ou essenciais pelo corpo (vitaminas, suplementos alimentares, drogas etc.) e tem liberdade de escolha no uso de técnicas e produtos (próteses, cosméticos, cirurgias plásticas etc.) (GOELLNER, 2013). Em outras palavras, mesmo que haja um repertório limitado de elementos estéticos, e que a responsabilidade para com o próprio corpo seja revertida ao indivíduo, o mesmo apropria-se da obrigação de responder pelos atos da própria vida. E "isso equivale à extradição do outro ${ }^{3}$, tornado perfeitamente inútil na gestão programática da existência, já que tudo concorre para a autarquia da célula individual" (BAUDRILLARD, 1990, p. 176) - o outro aqui pode ser tanto o modelo de estética quanto o Alter.

A tendência de transformar o sujeito "em escravo de sua identidade, de sua vontade, de sua responsabilidade, de seu desejo" falha quando consideramos criticidade e autonomia dentro da racionalidade dialógica Alter-Ego-Objeto (BAUDRILLARD, 1990, p. 176). Longe de vivermos em uma sociedade utópica, estável e fixa, a realidade está sempre sob a tensão causada pela necessidade de mudança. Dessa tensão surge a ideia de individualização, que deve ser interpretada como uma renegociação de posição social e a partir da qual se rejeitam os modos de ser e de agir disponíveis - o que sugere não-normatividade. Ora, no século XXI, sentir-se sendo uma exceção à norma torna-se mais atraente do que pertencer a uma coletividade (HALL, 2006), pois, no 'pós-humanismo', a individualização do sujeito "não se reduz ao hedonismo e ao psicologismo, mas implica, cada vez mais, um trabalho de construção de si, de tomada de posse do seu corpo e da sua vida" (LIPOVETSKY, 2004, p. 20-21).

No que tange à cibernética, seu desenvolvimento é pautado na observação do sujeito, dos tipos de interações que o mesmo estabelece com outros e com as máquinas eletrônicas (LÉVY, 1999) - o que reforça o caráter dialógico da realidade que transpassa nossa argumentação. Do uso da alta tecnologia na

\footnotetext{
${ }^{2}$ Expressão cunhada por Michel Maffesoli (2006).

${ }^{3}$ Grifo nosso.
} 
comunicação interpessoal e no controle das máquinas nasce a ideia de cibercultura, que interpretamos como uma expansão do sentido de cultura e da práxis do dia a dia. O que é, afinal, cultura? Segundo a explicação mais usual da palavra, cultura é um sistema de conhecimentos e crenças, de valores éticos e estéticos e de práticas sociais situado em contextos específicos - sejam eles locais ou globais. Em vista disto, acreditamos que a noção de cibercultura não contradiz o conceito corriqueiro, porquanto ela implica novos modos de agir e interagir (tipos de ação e relação social) e novos hábitos e costumes adquiridos (modos de uso tecnológico) que ampliam a rede de práticas no social.

A cibercultura, então, dista de uma subcultura ou de uma contracultura, visto que é um salto evolutivo da rede preexistente de práticas sociais e diz respeito à totalidade indistinta. E em plena era do desenvolvimento da informática e da comunicação, o corpo não está livre dos encargos advindos do acúmulo de conhecimentos e é intimado a adaptar-se à onipresença da tecnologia que, por sua vez, o torna mais veloz, preciso e transitório (STELARC, 1997). O indivíduo não apenas interage com as máquinas, mas também as têm como extensões do próprio corpo. "Com esta progressiva simbiose homem-máquina, fica cada vez mais difícil entender o que é o humano, na sua concepção tradicional" (COUTO, 2013, p. 176), já que essa é a realidade biopolítica do sujeito no século XXI. Nesses termos, inferimos que, mais adiante de ser a base da diversidade visível aos olhos, o corpo é a versão situada do humano na história social.

\section{CORPO INDETERMINADO E GÊNERO INCONDICIONADO}

Na cibercultura, estabelecer a distinção entre normalidade e anormalidade apresenta-se como um grande desafio (COUTO, 2013). Desejo, gênero, práticas sexuais e sexo, as quatro dimensões da sexualidade ${ }^{4}$, são administrados pelo saber no social - e não há meios de torná-los perceptíveis antes da sexuação do corpo e de um simbolismo cultural. Os reducionismos de senso comum (os estereótipos, por exemplo) têm o poder de nos fazer crer que tais dimensões são 'essências' que ocorrem sem causa exterior no corpo. A materialidade do indivíduo é tida, desse modo, como o epicentro de qualquer fenômeno sexual. Todavia, em um momento

\footnotetext{
${ }^{4}$ Arán (2012) nos diz que o gênero inteligível é aquele que mantém desejo, gênero, práticas sexuais e sexo dentro de uma continuidade. Guiados por este conceito, e com certa liberdade autoral, organizamos a sexualidade como sendo composta por quatro dimensões: (I) desejo, (II) gênero, (III) práticas sexuais e (IV) sexo.
} 
histórico de desconstrução do sujeito (HALL, 2006), também pela reapropriação e fluidez da corporalidade, tornou-se difícil determinar o que é saudável e o que é doentio na era da alta tecnologia.

Ainda que a Psicanálise tradicional tenha em consideração as dimensões da sexualidade, essa disciplina também situa o ponto de onde divergem apenas no corpo e no sujeito. Lembremos que os processos mentais são tidos como epifenômenos da matéria (do cérebro, no caso) - o que nos leva à questão da percepção individual - e que, por conseguinte, as práticas de significação e os sistemas simbólicos coletivos são deixados em segundo plano - estes são preocupações da Psicologia Social. Dito de outro modo, o núcleo rígido da teoria diz sobre uma visão cartesiana de mundo, onde o social é tido apenas como uma soma de indivíduos, e é dada pouca atenção ao trabalho imaterial, à produção de subjetividades, que nos posiciona como homem/ mulher, masculino/feminino e heterossexual/homossexual.

Contraditoriamente, para fugir do sentido popular de 'vida sexual' (coito e atos análogos), Freud elaborou uma concepção psicossexual do sujeito com base no simbolismo social (no totemismo, nas narrativas mitológicas e na antropologia) (apud BARBERO, 2005). O Complexo de Édipo, por exemplo, é explicado a partir da tragédia grega Édipo Rei - mito que, em representação simbólica, serve de exemplo para as identificações de gênero (Laio [pai/homem masculino] e Jocasta [mãe/ mulher feminina]). Como podemos, então, negar a ideia de que o que é considerado normalidade na sociedade são padrões de comportamento adquiridos? No que toca à sexualidade, normalidade e anormalidade, estas fazem parte de um regime de verdade que atende a uma relação sexista de poder, reforçando binarismos e dicotomias e apontando para inevitabilidades de existir. Assim sendo, as quatro dimensões são introduzidas em um continuum tido como 'sexualidade exemplar'.

Nessa concepção de poder, o nexo entre distinção anatômica, identificação correlata, tensão sexual e vida sexual dá um efeito de substância na sexuação do corpo, situando-o na estrutura de inteligibilidade disponível (ÁRAN, 2012). E, nesses termos, qualquer outro padrão de comportamento sexual é situado no campo da patologia, insanidade ou anormalidade. No momento em que outros discursos sociais apropriaram-se do psicanalítico, e tornaram-no público (séculos XIX-XX), instituiu-se uma 'normatividade' que controla e disciplina o sujeito através dos marcadores sociais de sexo/gênero. E é por meio das imagens e significações sobre o masculino e o feminino que a 'sexualidade exemplar' é sancionada como uma verdade absoluta (LOURO, 1998), estabelecendo a relação entre o simbólico (o significante pênis [a representação do falo] ou a vagina) e o imaginário (o que é próprio do homem e da mulher). Assim sendo, é fácil de entender como 
Todas as sociedades humanas se defendem contra o risco da falta de coerência, do inesperado e do incomum. Contra a angústia do desconhecido, o simbolismo social se apropria de todas as manifestações do corpo, seja ao influenciá-las diretamente, seja ao fazer entrar no interior de um sistema de sinais que lhe conferem sentido. [...] No seio do mesmo grupo, um repertório de sentimentos e de condutas é tido por apropriado a uma situação em função do status social, da idade e do sexo daqueles que são efetivamente atingidos, bem como de seu público (LE BRETON, 2009, p. 127).

Nas últimas décadas ${ }^{5}$, o grande debate em torno da sexualidade diz respeito a pôr em questionamento os essencialismos que tratam sexo, gênero e identidade como uma unidade. Foucault (1988) e Butler (2012), por exemplo, opõem-se a qualquer princípio de imutabilidade, tal qual a noção de identidade, e lutam contra as categorias sociais de sexo/gênero, que não dão conta da diversidade sexual. A ideia de sujeito é também revista por esses autores como um tipo de ação afirmativa, ou seja, de um lugar de onde se fala. Concluímos, então, que 'o lugar de onde se fala' é o corpo, a superfície, e que a interioridade é um contínuo vir-a-ser que desafia a estabilidade e a fixidez de 'ser algo', uma substância (homem/mulher, masculino/ feminino, heterossexual/homossexual etc.). Essa opinião sobre o sujeito não contradiz a presente argumentação de que o corpo é também uma tela de inscrição do momento histórico e de suas contingências sociais.

Tensões culturais como a homofobia e a lesbofobia, a pretexto de ilustração, constrangem o entrecruzamento das identificações de gênero pela educação de que certos atos, desejos e prazeres são proibidos e passíveis de punição, transformando o 'corpo subversor' em um alvo de ações 'reabilitadoras' (ofensas, estupros, espancamentos, 'curas'/conversões etc.). De tal sorte, alguns modos de inscrição sociocultural revelam sua natureza violenta e opressora. Os critérios de normalidade tornam-se, assim, o homem masculino e a mulher feminina cuja vida social e comportamento sexual não fogem ao anatômico. É interessante notar que qualquer LGBT pode ser entendido como 'corpo subversor', logo, está alojado na inteligibilidade. No entanto, a transexualidade, tida até o presente momento como um transtorno mental, é situada na ininteligibilidade, na psicopatologia. Por um viés crítico, podemos afirmar que, no caso do/a transexual, o que é inteligível é transformado em algo ininteligível para apoiar a carga histórica de práticas discriminatórias. Recordemos que a homossexualidade saiu da classificação de transtorno mental em 1973.

Independente da constatação de Lacan (1998b) de que "feminino e masculino não têm necessariamente de corresponder a mulheres e homens biológicos", mas

\footnotetext{
${ }^{5}$ Por últimas décadas procuramos dar a entender o desenvolvimento dos Estudos Gays e Lésbicos nos anos 80, surgimento da Teoria Queer nos anos 90 e os estudos recentes sobre corpo, gênero e sexualidade.
} 
"que se trata de posições no discurso" (BARBERO, 2005, p. 131), analisando textos científicos sobre a determinação sexual do indivíduo, Butler (2012, p. 157) assinala que "uns bons 10 por cento da população apresentam variações cromossômicas que não se encaixam exatamente no conjunto de categorias XX-fêmea, XY-macho". Isto é, uma parcela significativa de homens e mulheres classificados como tais têm uma porção genética indeterminada, mesmo que suas constituições físicas e funções reprodutivas sejam inquestionáveis. Em consequência, a presença do cromossoma $\mathrm{X}$ em homens e $\mathrm{Y}$ em mulheres, ainda que inativo, põe em xeque qualquer binarismo sexo/gênero.

A própria dicotomia homem/mulher não dá conta de todas as formas de vida no social. O/a intersex - o sujeito com genitália, testículos/ovários e cromossomos indeterminados - é tornado/a invisível. E, adiante de uma ininteligibilidade, a intersexualidade é transformada em inexistência. Melhor ainda, somos educados por um discurso histórico sobre a sexualidade que nos habilita como sujeitos sexuais dentro da intencionalidade de outrem, mesmo que Butler (2012) refute a ideia de agência dizendo que os sujeitos inteligíveis são apenas efeitos do discurso, e não causa. E é essa percepção sobre superfície (o corpo) e interioridade (uma suposta essência) normais que é comunicada pelos demais discursos sociais. Em suma,

A conclusão aqui não é que não seja possível fazer afirmações válidas e demonstráveis sobre a determinação sexual, mas, em vez disso, que as pressuposições culturais sobre o status relativo de homens e mulheres e sobre a relação binária do gênero estruturam e orientam as pesquisas sobre a determinação sexual. [...] A tarefa torna-se certamente ainda mais complicada quando entendemos que a linguagem da biologia participa de outras linguagens, reproduzindo essa sedimentação cultural nos objetos que se propõe a descobrir e descrever de maneira neutra (BUTLER, 2012, p. 160).

Se a interioridade é um contínuo vir-a-ser, a corporalidade revela-se como um desejo de 'ser algo': o mesmo, o Outro ou a diferença. Daí o corpo, na qualidade de projeção do espaço psíquico interior, ser também transitório (FREUD, 1996). A expressão ser algo é realmente problemática na teoria butleriana de gênero, porque dá a entender um sujeito sexuado universal, e não eventual, e, por consequência, uma identidade essencial, fechada em si. Porém, precisamos saber pôr em acordo preexistência interior (mente [individual]) e performatividade ${ }^{6}$ (corpo [social]). Butler $(2009 ;$; 2012), por exemplo, faz referência às performances de gênero das drag queens, mas falta com atenção para o fato de que nos/nas transexuais existe a certeza

\footnotetext{
${ }^{6}$ Performatividade é uma ideia desenvolvida por Judith Butler (2012), inspirada na teoria dos atos de fala, e diz sobre os efeitos que as práticas, instituições e discursos sociais exercem sobre o sexo, o gênero e o corpo. Para melhor aprofundamento sobre a teoria dos atos de fala, ver também: AUSTIN, 1990.
} 
de 'ser algo' - que é uma constatação, e não uma questão de performatividade (PROSSER, 1998). Perguntamos, então: tudo o que há no indivíduo é instável e contingencial? Uma resposta afirmativa nos faz cair em essencialismo social.

Uma subjetividade livre é imprevisibilidade (incondicionamento) e adaptabilidade (indeterminação) com liberdade de escolha: subverter ou adaptar-se à norma. Para que haja subversão, é necessária a presença de uma agência, o que é contraditório em Butler (2012), e, para que haja adaptação, são necessários os processos de identificação com o preexistente (com a performance, no caso).

Sobre queer, uma ideia não-normativa, a questão é: como se dá seu reconhecimento fora da estrutura de inteligibilidade? $\mathrm{O}$ próprio entrecruzamento das identificações de gênero, que sugere queer, diz sobre a combinação entre as performances de gênero já existentes. Como podemos observar, é necessário ter cautela até mesmo em avaliar a inexistência, pois se algo pode ser pensado, nomeado ou reconhecido, o objeto existe - objeto aqui pode ser uma coisa ou pessoa. Daí surge outra pergunta: há espaço para criatividade de gênero dentro da inteligibilidade disponível? Se a diferença é também socialmente produzida e constitui "os movimentos de normatização, discriminação e abjeção" (ARÁN, 2012, p. 147), logo, um possível reconhecimento de queer dá-se através de sua contraparte necessária, o normativo. Em vista disso, queer está dentro do campo do saber. A tendência de transformar o não-normativo butleriano em classificação é atraente, mas também constrói unidades ideológicas (percepções de mundo) subjacentes à normatividade e produz 'outros lugares de onde se fala' e superfícies que caem em outras categorias do mesmo.

Acreditamos que a nova provocação da sexualidade aos 'pós-humanos' é a superação dos significados políticos das categorias de sexo/gênero tradicionais, dos processos identitários anteriores, pois "a transgressão social tem diversas formas, significados e valores, segundo a sua possibilidade de propor ou instituir o novo, em lugar de se aproveitar gozosamente da destruição" (BARBERO, 2005, p. 134). Em outras palavras, criar uma nova categoria de sujeito (o/a queer, no caso) é reatualizar políticas de outrora, quando o importante é "pensar como cada indivíduo, na sua singularidade, vive a diferença para além das definições prescritivas da [homo/ ${ }^{7}$ heteronormatividade" (ARÁN, 2012, p. 148), pondo em relevo a experiência sexual como dado único, singular, e não coletivo, reiterável.

Uma vez que superfície (re-apresentação física) e interioridade (psique) são duas faces da mesma moeda, e o Eu próprio é uma referência verificável - ele/a é sensível e tem autoconsciência -, torna-se claro que a função da normatividade é

\footnotetext{
${ }^{7}$ Os colchetes são intervenção nossa com acréscimo de ideia.
} 
a de convidar uma subjetividade livre para uma percepção de mundo particular, e transformá-la em um ser submetido a uma autoridade. E já que a realidade comum é relacional (Alter-Ego-Objeto), não se pode negar a ideia de agência humana (Ego) com possibilidade de mudar o social - uma agência capaz de tornar qualquer sexualidade e corporalidade uma normalidade. Saudável e doentio são 'impressões de realidade' criadas por descrições históricas, impressões essas que tratam da arte de construir subalternidades (a doença [a diferença], no caso) a partir do que nos é familiar (da saúde [do normativo]).

Afinal, o Eu próprio existe no corpo ou ele/a é o corpo? De novo, a eterna problemática queer do 'existir' e do 'ser'. Salih (2012, p. 105) nos diz que "existir' o próprio corpo não é exatamente o mesmo que 'ser' o próprio corpo, pois a primeira expressão sugere que temos certo grau de agência e de escolha quando se trata da matéria da matéria". Nesses termos, a existência dá-se por meio de uma dimensão simbólico-discursiva fechada que também nos dá subsídios para sua subversão. No entanto, transgredir o simbólico-discursivo da estética não é subverter a materialidade do corpo para Butler (1993), visto que tal transgressão se dá "sobre um 'terreno' que já está discursivamente traçado e constituído" (SALIH, 2012, p. 105). Isto é, apropriar-se do corpo pela dimensão do preexistente não é existir, é apenas ser. Contraditório, não? Tão contraditório quanto estabelecer que o 'ser' é uma ilusão: eu sou isto (um enunciado constatativo); e o 'existir' é a realidade: eu sou uma materialidade discursiva (um ato performativo). No fim, ambas as perspectivas nos fazem chegar à mesma conclusão: fora da linguagem, não somos e nem existimos (BUTLER, 2015), pois não há introjeção do Alter-Objeto e nem percepção de si mesmo.

É óbvio que a existência se dá independente da percepção que se tem dela: uma árvore em uma floresta inexplorada para existir não depende de uma inteligência sensível (sentiencia) para percebê-la, ela apenas está lá. No que toca ao humano, porém, a autoconsciência de ter um corpo cognoscível fora do simbólicodiscursivo é impossível (LACAN, 1998a). Logo, o 'ser' (uma constatação do Ego) e o 'existir' (uma performance do sujeito), o corpo, são partes irredutíveis que compõem sua materialidade, porque o Eu próprio é tanto superfície quanto interioridade, e também é agência, mesmo que esteja sujeito à interpelação normativa de outrem (do Alter). Daí não nos apoiarmos de todo nos princípios butlerianos de sexo/gênero/ corpo, ainda que sejam válidos, porquanto o humano parece ser mais complexo do que esse sistema teórico pode conceber. Se reduzirmos do humano o social, o que sobra é uma existência fragmentada e confusa, senão meramente instintiva - e ele/a 'apenas estará lá'. Não há meios de mudar o social (uma ordem) instituindo que a 
real natureza de seus sujeitos é um estado de caos. E se o corpo é uma significação limitante, ele também pode ser ressignificado pela transgressão das formas que o 'normalizam' e o constrangem.

As apropriações estilísticas de corpo são locais. A sexuação do sujeito pode ser negociada de acordo com uma dinâmica cultural específica. Uma sexualidade aberta, por exemplo, pode não ser bem vista em países onde a homossexualidade e a transexualidade são consideradas práticas ilegais, mas no ocidente, em geral, notase uma crescente respeitabilidade para com o Outro e o 'poder existir em separado' (fora de categorias discretas). Mas ainda falta, para concluir, discutirmos o impacto das novas tecnologias na desinstitucionalização do corpo e nos deslocamentos da sexualidade.

\section{CULTURA DA ALTA TECNOLOGIA E CORPO HÍBRIDO}

"A ideia de 'identidade' nasceu da crise do pertencimento" (BAUMAN, 2005, p. 26), da necessidade de dar coesão entre o individual e o social e do receio do ostracismo. Por conseguinte, uma identidade fixa e universal é um projeto fantasmático de humano, criado na sopa cultural, tendo em vista a homogeneização de significações sociais. Então, identificar-se como sendo de um sexo/gênero é situar-se em um quadro de referências locais que diz sobre vestuário, formas do corpo e comportamentos - o que Butler (2012) chama de matriz heterossexual, e nós de condicionamento social. $\mathrm{Na}$ estrutura hierárquica do estilo clássico das relações de gênero (o patriarcado, no caso), as posições que seus sujeitos ocupam tendem a ser rígidas e inegociáveis, porquanto as definições tradicionais de homem e de mulher são tidas como dados naturais. Deduzimos, então, que é a tradição o estopim para grande parte das tensões políticas que envolvem as ditas minorias sexuais

Uma cultura tradicional costuma ser fechada a questões de gênero aquém do masculino e do feminino, já que é o contato com a diferença que gera o mal-estar e instiga a procura, a invenção e o descobrimento de 'outras identidades' (HALL, 2006). Logo, é a relação de proximidade entre culturas o fator que desencadeia a crise das identidades em um espaço demográfico específico, e que desafia sua coerência: a constatação (eu sou isto) torna-se comparável e questionável. Não obstante, o contato com o supralocal contesta a exatidão das determinações culturais. E, com isso, masculinidade e feminilidade tornam-se plurais, desnaturalizando certas expectativas de gênero historicamente situadas. 
Com o início dos processos da globalização (anos 70), a localidade foi invadida por outras coordenadas culturais de gênero, desintegrando ou reforçando 'velhas' identificações e produzindo 'novas' identificações sexuais - a tentação de transformar queer em categoria ilustra o último caso. Recordemos que toda cultura gira em torno dos sistemas de representação simbólica, do poder das palavras e das imagens, e que, com a compressão espaço-tempo, pelos mass media e pela Internet, as referências não-locais tornam-se simultaneamente intra-, inter- e transmundanas. Uma vez que há diferentes modos de interpretar o gênero segundo a cultura à qual está vinculado, e já que ele é também estética e estilística corporal (BENTO, 2006), o dito quadro referencial é deslocado de seu território representacional de origem nos introduzindo a novos estilos do corpo: a liberdade de vestuário, de formas do corpo, de comportamentos, de escolha das cores e cortes de cabelo dentre outros.

A cibercultura é um fenômeno próprio da globalização - é velocidade de informação e inovação tecnológica contínua. Esse tipo de cultura pós-moderna não apenas criou a realidade virtual, mas também tornou mais visível a virtualidade do real (LÉVY, 1996): o que é o corpo sexuado senão uma construção de sentido? (Afinal, corpo + gênero $=$ abstração virtual). $O$ mundo da significação é a virtualidade real, tendo começo no simbólico-discursivo, e não na rede de computadores. Isto é, a virtualidade do real é presença despercebida. Entretanto, é a realidade virtual que interconecta o não-físico (o espaço psíquico) com a corporalidade (a matéria) de um modo único: através da manipulação dos signos da linguagem pelo uso tecnológico.

A cultura da alta tecnologia tem implicações na sexualidade de seus sujeitos? Essa ideia nos chamou a desafio. É suficiente darmos uma olhadela para as novas práticas sexuais e modelos de afetividade para nos convencermos da certeza de que o 'pós-humano' está cada vez mais fora de qualquer tradição, e até mesmo do senso comum. A questão é: como se dão os processos ciberculturais de descentralização sexual?

Ser o que se é... Uma constatação, e outra expressão problemática. É possível ser performativo e constatativo ao mesmo tempo? Bem, o corpo não é uma mera descrição histórica, é também dado biológico - seja homem, mulher ou intersex. E, durante nossa argumentação, defendemos a tese de que superfície e interioridade podem ser 'duas faces da mesma moeda' - daí a necessidade, para grande parte dos/as transexuais, da Cirurgia de Redesignação Sexual (CRS). Poderia o gênero ser performance e constatação? De acordo com nossas leituras de Austin (1990), não nos opomos a tal hipótese, pois consignar a verdade do 'que se é' é desempenhar o estado do 'que se é' em algum nível. É complicado alojar o humano na simultaneidade da performance-constatação, visto que provoca certos determinismos teóricos. No 
entanto, afirmamos que a cibercultura é o espaço profícuo para os choques do ser com o existir.

O ciberespaço, Internet ou realidade virtual, é um ambiente de ressignificação da sexualidade e do corpo. É em meio às ondas eletromagnéticas que a matéria física transforma-se em abstração virtual, senão corpo virtual. A apresentação entre usuários de redes sociais (Twitter, Facebook, Instagram etc.) dá-se através de "representações gráficas (desenhos, fotografias, animações) ou textuais (descrições, caracterizações)" chamadas de avatares (PARREIRAS, 2009, p. 347). O avatar de um internauta é o exemplo perfeito de como o corpo ganha novos modos de expressão no espaço bidimensional de sociabilidade. Sendo um tipo de representação mental-material, a manifestação virtual de um corpo real põe em questionamento o dualismo descartiano corpo e mente: um perfil on-line, por exemplo, pode não representar a posição sexuada que o sujeito ocupa no ambiente tridimensional, mas pode simbolizar a autocriação do Eu próprio - por meio do uso do Adobe Photoshop ${ }^{8}$, por exemplo.

A autocriação, ou a autorrepresentação, do Eu próprio problematiza o tipo de relação que o indivíduo estabelece com o real anatômico. No caso do uso de photoshop, tal relação dá a entender conflito entre performance-constatação: a teleimagem é enquadramento social ou corporificação (embodiment) da certeza do 'que se é'? Se a primeira alternativa aponta para a primazia da estética cultural, a segunda alternativa significa livrar-se dos encargos do corpo biológico. Ou seja, a bidimensionalidade torna possível tanto o condicionamento quanto a indeterminação pela manipulação dos signos, sendo também um espaço favorável ao hibridismo de diferentes naturezas - seja cultural ou biológica. Em razão disto, Le Breton (2003) chama o corpo virtual de corpo supranumerário: ele é simultaneamente polimórfico, indeterminado e híbrido, assim como seus marcadores sociais de sexo/gênero, raça, classe etc.

Nossa intenção não é a de afirmar que não há relações de poder, classificações e categorizações no ciberespaço. Parreiras (2009), por exemplo, nota a presença de práticas discriminatórias, sexistas e homofóbicas, em uma comunidade virtual de homens gays (a Eper, no caso) - práticas essas orientadas pela reprodução dos papéis tradicionais de gênero (homem masculino/ativo e homem feminino/passivo, por exemplo). Mas, com a possibilidade do anonimato por meio de perfis falsos (fakes), o 'Eu-máquina' também está livre da normatividade coercitiva, pois "ninguém sabe quem está realmente do outro lado da tela" (LE, BRETON, 2009, p. 149). Logo, a realidade virtual é o lugar de "possíveis respostas às questões: Quem eu sou? O que eu poderia ser? Quem eu quero ser?" (WOODWARD, 2009, p. 17-18), visto que

\footnotetext{
${ }^{8}$ Software que edita imagens bidimensionais criado pelo Adobe Systems.
} 
Ela tem um efeito pluralizante sobre as identidades, produzindo uma variedade de possibilidades e novas posições de identificação, e tornando as identidades mais posicionais, mais políticas, mais plurais e diversas; menos fixas, unificadas ou trans-históricas (HALL, 2006, p. 87).

Se o ciberespaço é um lugar de transgressão das inibições culturais pela performance de imaginários ${ }^{9}$ erótico-subversivos, as condições materiais da cibercultura põem o corpo sensível ao alcance de experiências impossíveis de ele encontrar até então. Explicando melhor: Lacan (1998b), discutindo sobre a excelência do falo no simbolismo social, faz a distinção entre pênis flácido (o não-falo) e pênis ereto (falo) e chega à conclusão de que o falo é apenas uma possibilidade, só existe em parte e ninguém o tem de fato - "uma vez que ele é um símbolo" (SALIH, 2012, p. 120). Ou seja, ele em si não justifica as assimetrias de gênero, repercutindo nos modos pelos quais tais relações são percebidas. Inspirada por essa separação entre significantes, Butler (1993) propõe a ressignificação do símbolo fálico através de sua locação no corpo feminino, e em outras partes além da região pélvica (a mão, a língua, os dedos etc.), dando forma ao conceito de 'falo lésbico'10.

Já que o falo em si é outra construção virtual da linguagem, é possível pôlo em movimento tanto na dimensão morfológica do corpo quanto no sistema de objetos que orienta a produção de subjetividades no social. Butler (1993), porém, dissocia o falo lésbico do Objeto (do dildo, por exemplo), estabelecendo outros 'limites discursivos de sexo' ao dar pouca atenção aos efeitos da industrialização nas novas práticas sexuais. Ora, se a percepção da realidade dá-se por meio de uma racionalidade dialógica (Alter-Ego-Objeto) (MARKOVÁ, 2000), nenhum de seus elementos constituintes é redutível dos questionamentos sobre a verdade sexual, da mudança das performances de gênero ou, até mesmo, da busca pela felicidade, pois os chamados brinquedos sexuais (sex toys) também dizem sobre novos modos de organização da sexualidade.

As implicações dos objetos industriais na fenomenologia sexual precisam ser mais bem exploradas. $\mathrm{O}$ uso de alguns produtos sexuais (strap-on dildos, fleshlights ${ }^{11}$ etc.) aponta para a revisão do binarismo hetero/homossexualidade. A prática sexual chamada de inversão de papéis ${ }^{12}$ (sexual roleplay), por exemplo, rasura as fronteiras

\footnotetext{
9 Salih (2012, p. 117) interpreta o imaginário como sendo "o domínio das imagens e das fantasias conscientes e inconscientes".

${ }_{10}$ Para melhor aprofundamento sobre a subversão do símbolo fálico, ver: The lesbian phallus and the morphological imaginary (BUTLER, 1993, p. 28-57).

${ }^{11}$ Strap-on dildo é um tipo de pênis artificial utilizado na penetração de uma mulher em outra mulher, ou em um homem, na relação sexual, e flesblight é uma vagina, boca ou ânus artificial, em forma de uma grande lanterna (flasblight), na qual o homem introduz seu pênis durante a masturbação.

${ }^{12}$ Inversão de papéis, ou troca de papéis, é um padrão de comportamento sexual no qual a mulher desempenha um papel ativo (penetrador) e o homem um papel passivo (penetrado).
} 
antes bem definidas do erotismo. Apliquemos as seguintes perguntas: (i) Em uma relação sexual, o fato de uma mulher penetrar um homem com um pênis artificial torna o sujeito menos heterossexual?; (ii) e entre lésbicas, o uso do strap-on dildo torna o prazer sexual dependente dos critérios estéticos do gozo fálico?; (iii) e em uma masturbação, o fato de um gay penetrar uma vagina artificial torna o sujeito menos homossexual? Como podemos observar nos casos em questão, o Objeto também tira o humano de qualquer categoria discreta e mostra que a experiência sexual pode anteceder a sexuação do corpo - uma vez que o gênero é deixado em segundo plano.

Stelarc (1997) reconhece a robótica e a protética como extensões do corpo, e mesmo como novas configurações do humano. Então, nos parece que o novo humano - ou o pós-humano - caminha em direção a um estado sexual que dá outros contornos ao dualismo masculino/feminino por meio da interação do Eu com o órgão artificial. Se estivermos corretos, a autogestão e a autossuficiência sexual são efeitos da dita realidade alienígena, dos processos de individualização do sujeito que também desconstroem o ideal de completude homem e mulher biológicos. Já que a distinção anatômica e as identificações correlatas não dão mais conta da síntese do humano, a sexualidade torna-se mais multidimensional do que bidimensional (dois sexos = dois gêneros). E, com isso, as referências únicas e verificáveis, o pênis e a vagina, tornam-se dados não-normativos. E, uma vez que acreditamos que o humano é um ser experiencial, a patologização de sua vida precisa ser mais bem argumentada.

\section{CONSIDERAÇÕES FINAIS}

O pós-humanismo surge não apenas como uma era das inovações tecnológicas, mas também como o momento histórico de uma nova revolução sexual, sobretudo, a cibercultura que desconstrói o cinismo que transpassa as relações humanas: a normatividade, seja heterossexual ou homossexual, nada mais é do que um manual de etiqueta que educa o corpo e constrange os desejos profundos do sujeito. Desejo... Uma emoção ordinária? Le Breton (2009, p. 203) nos leva a crer que o desejo está além da continuidade de uma 'sexualidade exemplar', dada "sua complexidade, a especificidade provocada pela dessemelhança dos objetos" - objeto aqui é matéria, o que inclui o corpo. É justamente o que propõe a presente realidade, um leque ilimitado de possibilidades para desejar ter, ser ou, segundo Butler (2012), existir. 
Ao valer-se de estratégias repressoras, o sistema industrial transformou o corpo em uma peça do jogo econômico que legitima seu próprio poder de hegemonia, também dando forma a uma percepção de sexualidade 'normal'. Lembremos que a heterossexualidade compulsória obedece à lógica do máximo consumo, visto que o corpo feminino é tido como uma fábrica de novos consumidores e é controlado por um pressuposto de fidelidade - mulher como propriedade do homem -, enquanto a homossexualidade é tida como improdutiva. Hoje, com o advento da globalização, outras coordenadas culturais vulgarizaram o caráter regulatório do simbolismo local em favor de expectativas centradas na experiência subjetiva, e não coletiva. $\mathrm{O}$ importante para o 'pós-humano' é ser "cool'², flexível, hedonista e libertário, tudo isso ao mesmo tempo" (LIPOVETSKY, 2004). E, ao descentrar-se do Alter, em um estádio lacaniano do espelho inverso (LACAN, 1998a), o Ego se vê livre de todas as expectativas socialmente construídas em torno de seu corpo.

Digno de graça é o fato de que um espaço bidimensional de sociabilidade, e de interação do Ego com o Objeto (o ciberespaço, no caso), é o único lugar onde é possível ser humano sem amarras sociais, com todas as faces insidiosas e sublimes de nossas experiências no mundo tridimensional. Daí acreditarmos que o Eu próprio não está apenas na carne e nos ossos que compõem sua materialidade, mas também em qualquer elemento da tríade dialógica Alter-Ego-Objeto na qual o humano pode ser significado e ressignificado ininterruptamente. A constatação de que eu sou isto não está longe da significação de sou tudo isto (exterioridade e interioridade) ou sou qualquer coisa, pois, tal qual argumentamos, o corpo cognoscível só é possível através dos fenômenos de 'subjetividade-objetividade' - nos quais o Ego é tanto rejeição quanto aceitação do Alter-Objeto. E, entre o normal e o anormal, a diferença está sempre nos valores culturais atribuídos à alienação social, política e pessoal.

\section{REFERÊNCIAS BIBLIOGRÁFICAS}

AMORETTI, J. (2010). Movimentos sociais na América Latina e representações sociais de política. In: GUARESCHI, P.; HERNANDEZ, A CÁRDENAS, M. (orgs.). Representaçôes sociais em movimento: psicologia do ativismo político. Porto Alegre: EDIPUCRS, pp. 53-73.

ÁRAN, M. (2012). Por uma cartografia não-normativa das identificações e do desejo: algumas reflexões a partir das experiências trans. In: MISKOLCI, R.; PELÚCIO, Larissa (orgs.). Discursos fora de ordem: sexualidades, saberes e direitos. São Paulo: Annablume/Fapesp, pp. 139-153.

\footnotetext{
${ }^{13}$ Ser legal (tradução nossa).
} 
AUSTIN, J. (1990). Quando dizer é fazer: palavras e ação. Trad. Danilo Marcondes de Souza Filho. Porto Alegre: Artes Médicas.

BARBERO, G. H. (2005). Homossexualidade e perversão na psicanálise: uma resposta aos gays and lesbian studies. São Paulo: Casa do Psicólogo.

BAUDRILLARD, J. (1990). A transparência do mal: ensaio sobre os fenômenos extremos. Trad. Estela dos Santos Abreu. São Paulo: Papirus.

BAUMAN, Z. (2005). Identidade: entrevista a Benedetto Vecchi. Trad. Carlos Alberto Medeiros. Rio de Janeiro: Jorge Zahar Ed.

BAUMAN, Z. (2001). Modernidade líquida. Trad. Plínio Dentzien. Rio de Janeiro: Jorge Zahar Ed.

BENTO, B. (2006). A reinvenção do corpo: sexualidade e gênero na experiência transexual. Rio de Janeiro: Editora Garamond.

BUTLER, J. (2015). Relatar a si mesmo: crítica da violência ética. Trad. Rogério Bettoni. $1^{\mathrm{a}}$ ed. Belo Horizonte: Autêntica Editora.

BUTLER, J. (2012). Problemas de gênero: feminismo e subversão da identidade. Trad. Renato Aguiar. $4^{\mathrm{a}}$ ed. Rio de Janeiro: Civilização Brasileira.

BUTLER, J. (1993). Bodies that matter: on the discursive limits of "sex". New York/London: Routledge.

COUTO, E. S. (2013). Corpos modificados: o saudável e o doente na cibercultura. In: LOURO, G. L.; FELIPE, J.; GOELLNER, S. V. (orgs.). Corpo, gênero e sexualidade: um debate contemporâneo na educação. $9^{\mathrm{a}}$ ed. Petrópolis/RJ: Vozes, pp. 172-186.

FOUCAULT, M. (1988). A bistória da sexualidade 1: a vontade de saber. Trad. Maria Thereza da Costa Albuquerque e José Augusto Guilhon Albuquerque. Rio de Janeiro: Edições Graal.

FOUCAULT, M. (1988). Vigiar e punir: nascimento da prisão. Trad. Lígia M. Pondé Vassalo. $6^{\mathrm{a}}$ ed. Petrópolis: Vozes.

FREUD, S. (1996). O ego e o id e outros trabalbos. Trad. sob direção de Jayme Salomão. Rio de Janeiro: Imago.

GOELLNER, S. V. (2013). A produção cultural do corpo. In: LOURO, G. L.; FELIPE, J.; GOELLNER, S. V. (orgs.). Corpo, gênero e sexualidade: um debate contemporâneo na educação. $9^{a}$ ed. Petrópolis/RJ: Vozes, pp. 30-42.

HALL, S. (2006). A identidade cultural na pós-modernidade. Trad. Tomaz Tadeu da Silva e Guacira Lopes Louro. $11^{\text {a }}$ ed. Rio de Janeiro: DP\&A.

LACAN, J. (1998a [1958]). O estádio do espelho como formador da função do Eu. In: LACAN, J. Escritos. Trad. Vera Avellar Ribeiro. Rio de Janeiro: Jorge Zahar Ed, pp. 96-103.

LACAN, J. (1998b [1958]). A significação do falo. In: LACAN, J. Escritos. Trad. Vera Avellar Ribeiro. Rio de Janeiro: Jorge Zahar Ed, pp. 692-703.

LE BRETON, D. (2009). As paixões ordinárias: antropologia das emoções. Trad. Luís Alberto Salton Peretti. Rio de Janeiro: Vozes. 
LE BRETON, D. (2003). Adeus ao corpo. Trad. Marina Appenzeller. Campinas: Papirus.

LÉVY, P. (1999). Cibercultura. Trad.Carlos Irineu da Costa. São Paulo: Ed. 34.

LÉVY, P. (1996). O que é virtual? Trad. Paulo Neves. São Paulo: Ed. 34.

LIPOVETSKY, G. (2004). Metamorfoses da cultura liberal: ética, mídia e empresa. Trad. Juremir Machado da Silva. Porto Alegre: Sulina.

LIPOVETSKY, G. (1989). O império do efêmero: a moda e seu destino nas sociedades modernas. Trad. Maria Lucia Machado. São Paulo: Companhia das Letras.

LOURO, G. L. (1998). Gênero, sexualidade e educação: uma perspectiva pós-estruturalista. Petrópolis: Vozes.

MAFFESOLI, M. (2006). O tempo das tribos: o declínio do individualismo nas sociedades de massa. Trad. Maria de Lourdes Menezes. Rio de Janeiro: Forense Universitária.

MARX, K.; ENGELS, F. (1998). A ideologia alemã. Trad. Luis Cláudio de Castro e Costa. São Paulo: Martins Fontes.

MARKOVÁ, I. (2006). Dialogicidade e representações sociais: as dinâmicas da mente. Trad. Hélio Magri Filho. Petrópolis/Rio de Janeiro: Vozes.

PARREIRAS, C. (2009). Fora do armário... Dentro da tela: notas sobre avatares, (homo) sexualidades e erotismo a partir de uma comunidade virtual. In: DÍAZ-BENÍTEZ, M. E.; FÍGARI, C. E. (orgs.). Prazeres dissidentes. Rio de Janeiro: Garamond, pp. 343371.

PROSSER, J. (1998). Second skins: the body narratives of transsexuality. New York: Columbia University Press.

SALIH, S. (2012). Judith Butler e a teoria queer. Trad. Guacira Lopes Louro. Belo Horizonte: Autêntica Editora.

STELARC (Arcadiou, S.) (1997). Das estratégias psicológicas às ciberestratégias: a protética, a robótica e a existência remota. Trad. Flávia Saretta. In: DOMINGUES, D. (org.). A arte no século XIX: a humanização das tecnologias. São Paulo: Unesp, pp. 52-62.

WOODWARD, K. (2009). Identidade e diferença: uma introdução teórica e conceitual. In: SILVA, T. T. da; HALL, S.; WOODWARD, K. (orgs.). Identidade e diferença: a perspectiva dos estudos culturais. Trad. Tomaz Tadeu da Silva. $9^{\text {a }}$ ed. Petrópolis/Rio de Janeiro: Vozes, pp. 07-72.

Recebido: 31/07/2015

Aceito: 07/05/2016 